\title{
Editorial
}

\section{Cambiar las prioridades}

En el primer semestre de 1990 la producción agropecuaria y la actividad comercial han crecido por encima del indice general de actividad económica. Sin embargo, el sector industrial se encuentra estancado y la construcción experimenta un retroceso en términos absolutos.

Esta situación contrasta radicalmente con los mismos datos referidos a los 3 años precedentes, cuando los sectores más dinámicos eran precisamente la construcción y la industria.

Esta evolución es aun más grave si la ponemos en relación con los otros indicadores básicos de la coyuntura económica: la inflación y la balanza de pagos.

Pese al importante incremento de la actividad agropecuaria, los precios de los alimentos experimentan el mayor crecimiento entre los componentes del IPC (32.13\%), siendo el único que sube por encima del índice general, $(27.32 \%)$, seguido por precios de la vivienda (25.85\%). El sector agropecuario no parece pues responder conscientemente a las leyes del mercado quizá por el carácter oligopólico que genera la actual distribución de la propiedad agrícola (recomendarlamos al gobiemo que la prometida ley antimonopolios se aplicase en primer lugar al sector más concentrado de nuestra economía, cual es la producción agropecuaria).

Por otro lado, analizando la composición de las exportaciones enero-mayo, observamos un importante crecimiento en el volumen de la agroexportación que explica básicamente la mejora en la actividad del sector (incremento de un $17 \%$ en la exportación de café respecto al 
mismo período en 1989 y del 169.2\% en la exportación de azúcar). Pero el panorama es más desalentador si analizamos el valor de esas exportaciones: una caída del $-27.7 \%$ en los ingresos por exportación de café, y un incremento del $170.1 \%$ en la exportación de azúcar. El saldo de la balanza comercial, experimenta una mejora en el volumen exportado $(22.4 \%)$ y un deterioro en el saldo $(-27.6 \%)$, originado en un deterioro relativo de la relación exportaciones a importaciones.

En consecuencia, nuestro país está exportando más, pero a menor precio (menor valor agregado) que en el mismo período del año pasado.

Si nos fijamos en las exportaciones de productos no tradicionales, un aumento en el volumen del $8.1 \%$ significa un incremento en los ingresos del $20.4 \%$.

Pareciera que los resultados de la actividad económica reflejan una orientación de la economía justo hacia donde no debe ir desde el punto de vista de la eficiencia del mercado: potenciación de actividades agroexportadoras tradicionales en un contexto de mercados extemos que muestra un claro deterioro de los términos de intercambio para estos productos; incapacidad para generar un cambio en la cultura agropecuaria que permita estabilizar los precios del principal componente del IPC y ún deterioro de las actividades capaces de generar un mayor crecimiento de la productividad y el valor anadido, cuales son las industriales y de la construcción.

No parece que esta orientación refleje un especial momento de la coyuntura, sino que, como senalábamos en el anterior número de Realldad, las prioridades de política económica establecidas por el gobiemo auguran una profundización en la misma línea.

La situación es más preocupante si recordamos que el Plan de Desarrollo del Gobiemo, prevé para 1990 un crecimiento del PIB de un $2.1 \%$ en términos reales, que dado un estancamiento en el consumo interno (crecimiento del $0.2 \%$ ) y una fuerte caída de la inversión $(-44.5 \%)$, se sostendria en un aumento de las exportaciones del 49.2\%. Sin embargo, en el período enero-mayo, las exportaciones han caído un $-6.4 \%$ respecto al mismo período del ano anterior. $Y$ las importaciones, cuyo comportamiento previsto era de una disminución en un $-11.6 \%$, ha aumentado de enero a mayo en un $5.3 \%$.

Ante semejante desajuste entre el comportamiento de las variables reales respecto a las previstas en el que es el principal objetivo de la polftica gubermamental (el sector exterior), resulta imprescindible realizar un estuerzo colectivo de reflexión, en el cual participen todos los 
sectores productivos, los trabajadores y el propio gobierno, que permita una reorientación de las prioridades en el manejo de la coyuntura. De otro modo, la inflación, el déficit externo y el estancamiento de la productividad y los salarios pueden abocarnos al colapso económico. 